\title{
Графический редактор ADOBE РHOTOSHOP как способ создания электронных дидактических материалов к занятиям в ДОУ
}

\author{
Романов Д.П., студент, \\ ГБПОУ РС (Я) «Вилюйский педагогический колледж \\ имени Н.Г. Чернышевского», \\ 2. Вилюйск \\ E-mail: Lenal_mrd@mail.ru
}

Научные руководители: Лебедева Л.А., Гуляева С.А.

Система образования предъявляет новые требования к воспитанию и обучению подрастающего поколения, внедрению новых подходов, которые должны способствовать не замене традиционных методов, а расширению их возможностей.

Развитие общество сегодня диктует необходимость использования информационных и коммуникационных технологий (ИКТ) в учебном процессе посредством рисования в программе Adobe Photoshop. Они могут полностью заменить традиционные средства обучения (иллюстративные плакаты, схемы, таблицы, анимации) и позволяют полно и интересно проиллюстрировать во время обучение детей в ДОУ.

Растровый графический редактор - специализированная программа, предназначенная для создания и обработки растровых изображений, то есть графики, которая в память компьютера записывается как набор точек, а не как совокупность формул геометрических фигур. Подобные программные продукты нашли широкое применение в работе художников-иллюстраторов, при подготовке изображений к печати типографским способом или на фотобумаге, публикации в интернете.

Растровые графические редакторы позволяют пользователю рисовать и редактировать изображения на экране компьютера, а также сохранять их в различных растровых форматах, таких как, например, JPEG и TIFF, позволяющих хранить растровую графику с незначительным снижением качества за счёт использования алгоритмов сжатия с потерями, PNG и GIF, поддерживающими хорошее сжатие без потерь, и BMP, также поддерживающем сжатие (RLE), но в общем случае представляющем собой несжатое «попиксельное» описание изображения. Таким образом есть необходимость использование электронных дидактических материалов студентов к занятиям в ДОУ.

Постановка проблемы: Отсутствие эффективных электронных дидактических материалов к занятиям в ДОУ.

Цель: изучить особенности разработки электронных дидактических материалов к занятиям в ДОУ посредством программы ADOBE PHOTOSHOP.

Электронные дидактические материалы к занятиям в ДОУ разработаны с помощью программы Adobe Photoshop.

Применение электронного дидактического материала к занятиям:

—_ формирует и развивает информационную компетенцию дошкольников;

- ускоряет передачу знаний;

- увеличивает объем выполнения заданий на занятие;

- п повышает познавательную активность и мотивацию усвоения знаний; 
В производственной и государственной практик студенты дошкольного образования должны апробировать данную работу на занятиях в ДОУ. Данную технологию должны использовать в основном для:

- для ознакомления новой темы - объяснение нового материала с демонстрацией на компьютере (используя один компьютер);

- д для закрепления полученных знаний.

Для начала запустим Adobe Photoshop CС и создаем новый файл, выбираем (см. рис 2.3.1.1 Запуск программы). Тип документа “Международный формат бумаги”, размер формата вставим А5 и нажимаем на “ОК” (см.рис. 2.3.1.2 Размер бумаги).

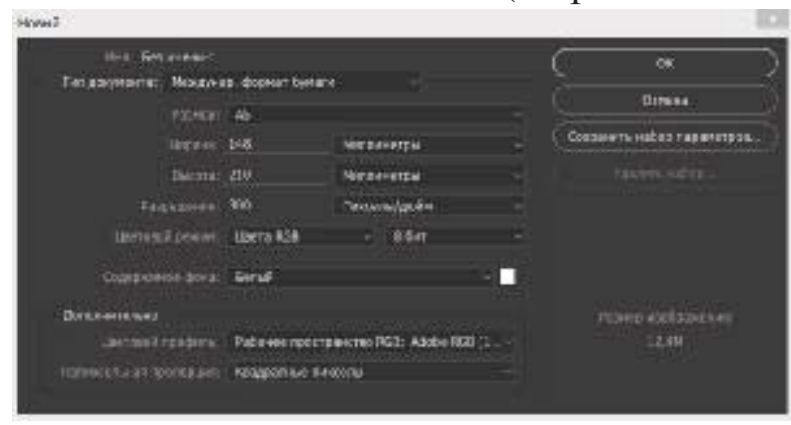

Рис. 2.3.1.1. Запуск программы

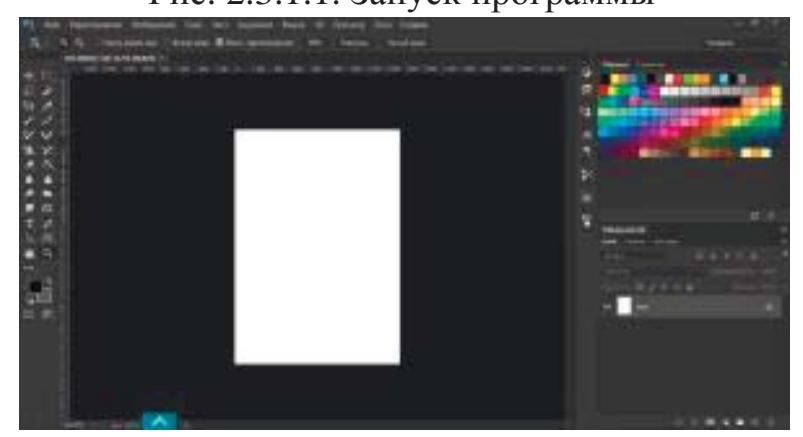

Рис. 2.3.1.2. Размер бумаги

Далее можно приступить к разработке.

Во-первых, мы не станем пока трогать слой с названием “Фон”, мы создадим новый слой. Так, нажимаем на значок в нижнем углу справа, или же (Ctrl+Shift+N).

Как вы заметили в правом нижнем углу появился новый слой “Слой 1”. Также можно переименовать этот слой дважды нажав ЛКМ на имя слоя, чтобы в будущем не запутаться какой слой мы редактируем. Итак, слой мы назвали “Линии” (см. рис.2.3.1.3 Слои).

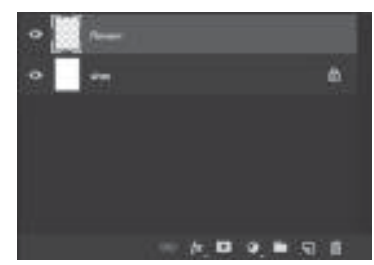

Рис. 2.3.1.3 Слои

Выберем инструмент “Прямоугольник со скругленными краями” (U). C помощью его делаем форму прямоугольника, после этого выберем ширину штриха фигуры, пишем 1.12 пт и нажимаем “ENTER” (см. рис.2.3.1.4 «Прямоугольник», «Свойства»). 

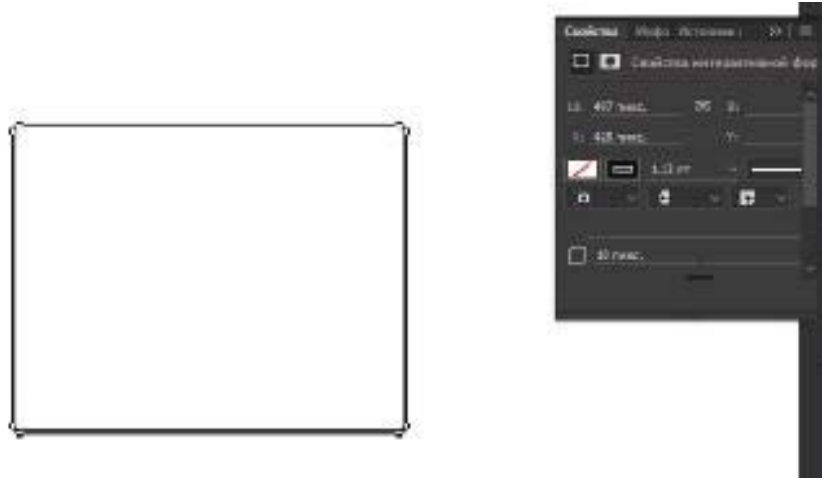

Рис. 2.3.1.4 «Прямоугольник», «Свойства»

Таким же образом создадим восемь таких фигур вокруг зоны. Результат будет выглядеть примерно так: (см. рис. 2.3.1.5 «Прямоугольники»)

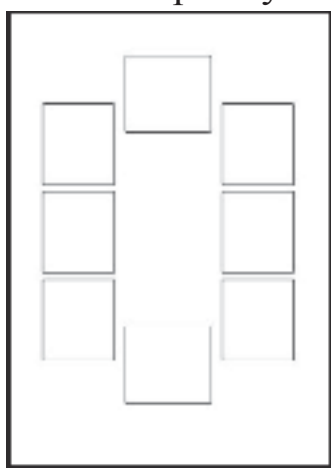

Рис. 2.3.1.5 «Прямоугольники»

Создаем новый слой и выбираем инструмент “Кисть” (В), выбираем подходящий цвет и в самом верху прямоугольника внутри рисуем фигуру белки. Можно приблизить экран инструментом “Лупа” (Z) Q , чтобы было хорошо видно (см. рис. 2.3.1.6. «Белка, зарисованная с помощью инструмента «Кисть»).

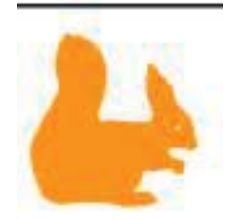

Рис. 2.3.1.6. Белка, зарисованная с помощью инструмента «Кисть»

Теперь нам надо сделать белку более реалистичной. Создаем новый слой, выбираем подходящий цвет и рисуем тени и глаза.

Вот что примерно должно получиться:

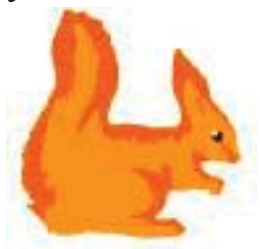

Так же способом выполняем изображение других рисунков. 

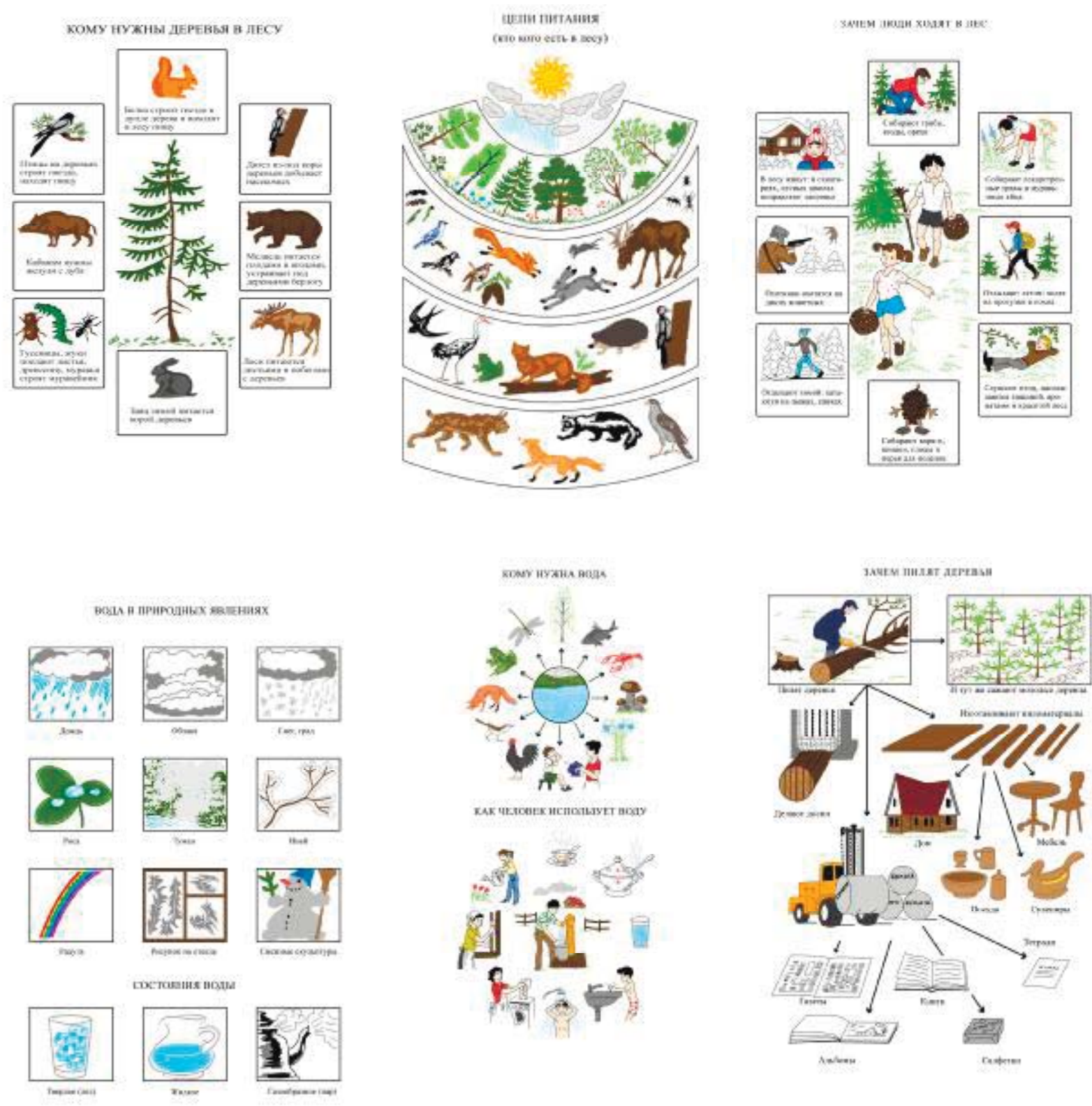

Новые требования, предъявляемые к воспитанию и обучению подрастающего поколения, внедрению новых подходов, которые должны способствовать не замене традиционных методов расширению возможностей использования информационных и коммуникационных технологий (ИКТ) в учебном процессе посредством рисования в программе Adobe Photoshop. Они могут полностью заменить традиционные средства обучения (иллюстративные плакаты, схемы, таблицы, анимации) и позволяют полно и интересно проиллюстрировать во время обучение детей в ДОУ.

Растровые графические редакторы позволяют рисовать и редактировать изображения на экране компьютера, а также сохранять их в различных растровых форматах, таких как, например, JPEG и TIFF, позволяющих хранить растровую графику с незначительным снижением качества за счёт использования алгоритмов сжатия с потерями, PNG и GIF, поддерживающими хорошее сжатие без потерь, и ВMP, также поддерживающем сжатие (RLE), но в общем случае представляющем собой несжатое «попиксельное» описание изображения. Таким образом есть необходимость использование электронных дидактических материалов студентов к занятиям в ДОУ. 
Список литературы:

1. http://en.wikipedia.org/wiki/Adobe_Photoshop

2. http://ru.wikipedia.org/wiki/Adobe_Photoshop

3. http://window.edu.ru/catalog/pdf2txt/176/79176/59829?p_page=5

4. http://stockers.ru/articles/rastr/

5. http://ipic.su/blog/2010/11/17/rgb-cmyk-xyz

6. http://www.xserver.ru/computer/graphic/obsh/3/

7. http://www.compkursy.ru/photoshop/

\section{Исследование стационарности низкочастотных микросейсмических сигналов пункта Удыль}

Рябинкин К.С., Пупатенко В.В., Институт тектоники и геофизики им. Ю.А. Косыгина ДВО РАН, 2. Хабаровск E-mail: kostya-rowan@mail.ru

Научный руководитель: о.г.-м.н., профессор Трофименко С.В.

Изучены статистические параметры микросейсмических сигналов пункта Удыль, сделан вывод о несоответствии статистического распределения скоростей смещения нормалному. Установлен один из источников генерации микросейсм в диапазоне более 2 Гц. Проанализирована зависимость дисперсии микросейсмического сигнала от продолжительности интервала оценки. Выявлен участок относительной стабилизации дисперсии на коротких интервалах до 100 мин., в то время как при длительности в несколько часов дисперсия не стабилизируется.

В настоящей работе для изучения статистических параметров микросейсмических сигналов используются записи микросейсм, полученных во время полевых сейсмических наблюдений вблизи оз. Удыль (Ульчский p-н Хабаровского края). Сейсмические наблюдения проводились в течение десяти дней с 23 июля по 1 августа 2014 г цифровым регистратором с непрерывной записью REF TEK-130, оснащённым широкополосным сейсмометром REF TEK 150-120. Основная задача данных исследований - изучение строения земной коры.

Уровень микросейсмического шума в районе пункта наблюдений (рис. 1) невысокий. На рис. 1 кривые спектральной плотности мощности (СПМ) для Xканала (ориентированного на север) соответствуют значениям вероятности 5, 50 и 95\% за всё время наблюдений. Также приведены модели низкого (NLNM) и высокого (NHNM) шума [13]. На всём рассмотренном диапазоне периодов (0.1-10 c) медианный уровень микросейсмического шума ближе к NLNM, чем к NHNM. 